\title{
Auditory Efferent System; A Review on Anatomical Structure and Functional Bases
}

\author{
${ }^{1}$ Department of Audiology, University of Social Welfare and Rehabilitation Sciences, Tehran, Iran \\ ${ }^{2}$ Department of Otolaryngology, School of Medicine, Iran University of Medical Sciences, Tehran, Iran \\ ${ }^{3}$ Department of Audiology, School of Rehabilitation, Tabriz University of Medical Sciences, Tabriz, Iran \\ ${ }^{4}$ Department of biostatistics and epidemiology, Zanjan University of Medical Science, Zanjan, Iran
}

Yones Lotfi ${ }^{1}$, Abdollah Moossavi ${ }^{2}$, Mohanna Javanbakht ${ }^{1 *}$, Nayiere Mansouri ${ }^{1,3}$ and Soghrat Faghih zadeh ${ }^{4}$

Submission: August 30, 2019; Published: October 10, 2019

*Corresponding author: Mohanna Javanbakht, Department of Audiology, University of Social Welfare and Rehabilitation Sciences, Tehran, Iran

Abstract

Background and Aim: In everyday life, auditory stimuli with different levels of intensity and various conditions from silence to the presence of competitive noise are presented. The auditory efferent system, which runs parallel to the auditory afferent one throughout the entire auditory pathway from the cortex to the cochlea, is involved in complex auditory processing such as speech recognition and auditory localization in noise. In this review, we have a focus on published researches about the structure and functions of the auditory efferent system.

Findings: In the anatomic view, the auditory efferent system can include circular or serial chain paths at different levels. For evaluating the performance of this system in humans, the only accepted non-invasive method is the application of the OAE suppression test, which examines the specific cycle in the caudal part of the efferent system and provides no direct information about the performance of the rostral parts. Various studies have reported the probable role of auditory efferent pathways in many auditory processes and this system damage in hearing impairment such as tinnitus and central auditory processing disorder.

Conclusion: Considering the anatomy and the various centers involved in the auditory efferent system, as well as the definitive and possible functions described around it, it seems that more studies require in this field. Based on the last published studies, the role of the auditory efferent system is prominent in hearing processing, especially in challenging and difficulty auditory conditions.

Keywords: Auditory Efferent System; Olivocochlear Bundle; Corticocollicular; Speech perception in Noise; Localizatio; Selective Attention

Abbreviations: S-ABR: Speech Evoked ABR; S-ABR/coN: Speech Evoked ABR with Contralateral Noise; ADHD: Attention Deficit Hyperactivity Disorder; MGB: Medial Geniculate Body; IC: Inferior colliculus; SOC: Superior Olivary Complex; MOCB: Medial Olivocochlear Bundle; LOCB: Lateral Olivocochlear Bundle; SNR: Signal to Noise Ratio; TEOAE: Transient Evoked Otoacoustic Emission

\section{Introduction}

For a long time, sensory afferent paths were known as a way of connecting living organisms to their surroundings, creating a one-way route from sensory receptors to processing centers at higher levels to each sensory processing cortex. In the case of the auditory path, the auditory pathways from the peripheral hair cells of the cochlea to the auditory cortex are accurately identified and evaluated behaviorally, physiologically and through electrophysiological tests [1].

The discovery of neuronal pathways from the central nervous system to the nuclei and receptors of the peripheral hearing system [2-4] led to a change in the look at the auditory processing pathways and developed the theory of "central control of sensory inputs". This theory focused based on that brain and high processing levels can control or at least, make changes in the signals received from the sensory receptors and afferent pathway [5,6]. Researchers have defined the "efferent system" in the auditory system as centrifugal pathways that run to the inner ear hearing and balance peripheral receptors [2].

According to the findings of the further studies, the auditory efferent system was parallel to the auditory afferent system with the same volume and structural characteristics from the auditory cortex to the MGB, IC, SOC, and CN [5,7-10]. Direct paths and cycles from the level of the auditory cortex to the thalamic levels of MGB, followed by the levels of the brain stem IC, LL to SOC 
and $\mathrm{CN}$, and finally the inner ear was described. Some of which represent series and hierarchical processing and some other paths suggest parallel processing. Identifying and explaining the structural and functional characteristics of the peripheral levels of auditory efferent system are likely to be made earlier due to the availability of the route.

Indeed, the discovery of the SOC's neural pathways towards the inner ear can be seen as the starting point in the modern scientific viewpoint of the auditory efferent system, which was carried out by Rasmussen in 1946, although it was a crosssectional look at the most peripheral parts of the auditory efferent system [4]. After more than 60 years of introducing auditory efferent system by the Rasmussen, more studies have been done on the structure and function of this path at its various levels but many questions in this field are unknown yet. With a review of published articles in the field of auditory efferent system, can conclude that the pathways of the auditory efferent system are less well-known than the afferent auditory pathways, one of its factors can be the structural complexity of cycles and possible series or sequential chains in this pathway [11]. Therefore, we have a view on structural studies and explain the nuclei and the connections of this pathway based on published references. Then some of the known functions of the auditory efferent system are considered.

\section{Anatomy and Structure of the Auditory Efferent System}

The auditory efferent system can be divided into two main parts:

a. The rostral part or centrifugal pathway, which itself includes corticothalamic and corticocollicular pathways.

b. The caudal part or the olivocochlear system, whose structure and function are more studied and more known than the rostral part.

\section{Rostral or Centrifugal Part}

This section originates from several centers in the auditory cortex and its messages are sent to various nuclei of thalamic and brainstem such as MGB and IC [11-13]. The centrifugal pathway, which begins from the auditory cortex and is followed up to the IC, can be divided into two main corticothalamic and corticocollicular systems [8]. These two systems are the main pathways of the auditory cortex, which for years served as the only outputs of the auditory cortex to the cores of the auditory system, but later studies identified fewer volume paths from the auditory cortex to the subcortical nuclei, such as SOC, CN, LL [14].

The corticothalamic system, which is the largest volume of the corticofugal pathway [15], has the frequency tonotopic and spatial topography and sends messages from the V and VI layers of different regions of the auditory cortex to different parts of the MGB (the most important thalamic nucleus) [16]. Accordingly, the tonotopic regions of the auditory cortex send the highest output to the MGB tonotopic sections [8]. Morphology and the structure of the axons of this path depend on the origin and destination of the axon. The narrower fibers have smaller buttons terminals and end in the ventral parts (generally the tonotopic regions), whereas thicker axons, with larger terminals, end in the posterior and middle portions (generally non- tonotopic regions) [17].

The afferent and efferent pathways between the auditory cortex and the MGB provide a vital afferent- efferent cycle. Although the general performance of the auditory efferent system is the modification of the afferent pathways information and assistance to auditory processing in challenging auditory situations, detailed and published information on functional details of this system is not available. The corticocollicular system includes the efferent pathways to the midbrain and the IC. This pathway involves less volume of the efferent system than the corticothalamic pathway [15], but still has a tonotopic and topographic organization [18]. For many years, it was believed that IC as the main nucleus in this pathway received its main input from the neurons of the $\mathrm{V}$ layer of the auditory cortex, and these enter the dorsal and external nucleus of IC $[8,9]$, which are commonly referred to as auditory attention-related structures [19]. However, in subsequent studies, the involvement of VIlayer cells was also confirmed in the corticocollicular pathway [20].

Due to the size of the IC, internal neural connecting in IC and the specific position of this nucleus as the common boundary between the rostral efferent pathways and the entrance to the caudal efferent pathway [21], as well as the confirmed connections of cortical efferent fibers with afferent pathway fibers at the IC level [22] led to a special focus on the role of the IC on the efferent pathway. Huffman and Henson defined the probable three-way synaptic pathway from the auditory cortex to the cochlea, which transmitted the information from the auditory cortex to the IC and then transferred to the SOC, then through the OCB to the cochlea (caudal efferent pathway).

Although this pathway was not identified in cellular studies, there was some evidence in favor of this theory, including the fact that cortical axons end in the same parts of the IC whose cells carry messages to the SOC [23]. Some researchers have defined topical feedback cycles in this system, which include rostral pathway cycles, including auditory cortex, thalamus (MGB), and IC and the cycles of the lower or caudal part of the path include the connections between brain stem nuclei, IC, SOC, and CN.

In this model, IC is also the common boundary between the upper and lower cycles of the efferent pathway, which has the ipsilateral and contralateral connecting with other brain stem nuclei and send more fibers outputs to the ipsilateral SOC [11]. The bilateral pathways from the IC to the $\mathrm{CN}$ are also identified $[6,24]$. Cellular studies have also been published to confirm the chain or cycle paths in the pathway for the auditory efferent 
system, some of which were in favor of chain trails [14,25,26], and some were in confirmation of feedbacks in the efferent pathway [8]. These findings require further studies to explore communication between the centers on this path.

In recent years, communications have been found between the major centers of corticothalamic and corticocollicular pathways, MGB and IC $[27,28]$. Direct inputs from the auditory cortex to SOC and CN are defined, which are less than $10 \%$ of the inputs to the IC [8]. Efferent inputs from the auditory cortex to other non-auditory centers such as pons, striatum, cerebellum, tegmentum, and amygdala have also been found [8,29-31], which are beyond the scope of this review article.

\section{Caudal part or Olivocochlear Bundle}

On the contrary, the rostral part or centrifugal pathway of the auditory efferent system that has less well-known structure and function, the Caudal part of the auditory efferent system or olivocochlear bundle, has been carefully studied in animal and human studies, and its structure and functions were taken into consideration. The olivocochlear bundle, the pathway which was discovered by Rasmussen in 1946 [4], has two general components. One of the segments is known as the lateral olivocochlear bundle (LOCB) and the other as the medial olivocochlear bundle (MOCB) group [30]. Some researchers have named these two parts as the Lateral Efferent System and the Medial Efferent System [32].

The lateral olivocochlear bundle or lateral efferent system, including non-myelinated fibers, is generally derived from the lateral SOC portions and ends on the dendrites of the auditory afferent pathways coming out from the inner hair cells, and sometimes on the inner hair cells bodies themselves [33,34]. The most fibers of LOCB are in the middle and basal parts of cochlea i.e. the high-frequency regions, which have been observed in animals with high-frequency hearing, and in these animals, the LOCB has received a large proportion of auditory efferent system $[32,35]$. But in humans and mammals with dominant hearing in lower frequency regions, the role of MOCB is much more pronounced and it seems that the larger medial olivary nucleus than the lateral olivary nucleus in humans also confirms the role and importance of MOCB in humans [32,36].

The medial olivocochlear bundle originates from the medial SOCs and terminates at the large terminals at the inferior end of the outer hair cells, which is on the contrary of LOCB, the most fibers of MOCB go to the contralateral outer hair cells, and make the junctional path $[30,37]$. The synapses of the medial efferent system are created in the earlier growth stages than the lateral efferent system and after the discontinuation of the axons, they also show slow degeneration [32]. MOCB fibers in the internal auditory canal before being exited from the habenula were myelinated, and this led to a significant structural difference. Therefore, the MOCB fibers could be directly stimulated electrically and recorded their response, which was not possible in non- myelinated LOCB fibers. The acoustic stimulation of the
LOC and the MOC fibers have not been approved. Therefore, the published information on the LOCB path is much more limited but is more comprehensive in terms of the functional details of the MOCB path [6].

\section{Auditory Efferent System Functions}

It seems that the general performance of the auditory efferent system is manipulating the messages or functions of the sensory afferent centers in the lower levels. Due to the prevalence of inhibitory neurotransmitters in this pathway, most of these effects are caused by interventions to lower levels nuclei either in the form of a chain or through cycles at different levels of auditory efferent system. The auditory efferent system improves hearing accuracy, or auditory processing in challenging conditions such as hearing in the presence of background noise, dichotic listening etc. In the following, the results of published studies in the field of effects and functions of the auditory efferent system at the rostral and caudal levels are discussed. Of course, in this area, the knowledge of the importance and performance of the caudal part of the olivocochlear bundle are much higher.

\section{Functional Effects of the rostral or Centrifugal part}

When the responses of IC cells were recorded as the target of the corticocollicular pathway by stimulating the associated cortical regions, it was observed that the response to the characteristic frequency was improved, and response to the lateral frequencies was inhibited [30]. It seems that wider section of the auditory pathway is allocated to the frequencies that are stimulated in the auditory cortex and depending on the cortical regions. Due to corticofugal efferent pathways, the response of the lower centers of the auditory path was corrected, these findings were recorded in mice and bats [38,39]. Based on this, it seems that the function of central centrifugal efferent pathways at thalamocortical levels, which is more likely to be considered as cortico-thalamo-cortical cycles, and at the corticocollicular levels, leads to the allocation of more neurons in lower levels to stimuli of particular importance for humans.

Although a significant part of auditory skills is because of efferent pathways on the process of auditory processing, yet the same and approved methodology is not available for direct and clinical examination of the rostral or Centrifugal part [40]. Recent studies in the field of behavioral and electrophysiological auditory examination have shown evidence of the work of this system in complex auditory processes such as speech perception and sound localization in noise [16]. Tracking the effects of corticocollicular pathways from IC on SOC, and then on the cochlea (through the MOC pathway) also indicates an improvement in the frequency characteristic through generally inhibitory (and in some cases, excitation) effects that control the IC function by increasing spontaneous activity in nerve fibers and effects with frequency characteristics on cochlear responses were shown $[30,41]$. 


\section{Functional Effects of Caudal Part or Olivocochlear Bundle}

Before we look at the function and effects of the MOCB, we look at the limited findings and assumptions given about the effects of the LOCB on the auditory system function.

\section{Lateral olivocochlear bundle (LOCB)}

It is difficult to investigate the effects of LOCB stimulation due to its non-myelinated structure and its association with the effects of MOCB [30]. Therefore, general studies have been conducted indirectly by stimulating LOC sections in SOC or IC. The delay in the efferent effects of LOCB due to the nonmyelinated of fibers in this path is longer than the MOCB pathway and results in very slow effects (with a time constant of minutes) [42]. Activating the LOC origin cells in the superior olivocochlear complex with the topical application of Noradrenaline has increased the spontaneous response and excited the auditory nerve fibers' responses [43].

Subsequent studies have shown that LOC affects upperthreshold neural responses, which are not always inhibitory. In fact, in various studies, due to the electrical stimulation of different regions of the IC, which were related to the LOC, it was observed that some areas had an inhibitory effect on the response of the auditory nerves, and the stimulation of other areas led to an increase in responses $[42,44,45]$. Therefore, the theory of binary stimulatory and inhibitory effects of LOC is the most dominant theory. It also justifies some effects of LOCB fibers in reducing acoustic trauma and hearing protection against noise by decreasing TTS through inhibiting neurotransmitter release from inner hair cells $[46,47]$. But in any case, due to the lack of the direct stimulation of the LOCB, our understanding of the precise performance and effects of this part of the caudal auditory efferent system is less than the MOCB.

\section{Medial olivocochlear bundle (MOCB)}

The direct electrical stimulation of MOC neurons, which is generally obtained through the stimulation of crossing fibers in the fourth ventricle floor, can change the movement of outer hair cells and decreases the active amplification of the traveling wave in the cochlea. Electrical stimulation of MOC neurons with reducing the amplitude of the basilar membrane vibrations may lead to changes in the fine-tuning curves of the inner hair cell and auditory nerve $[48,49]$.

MOC neurons with the release of the acetylcholine neurotransmitter at the terminals attached to outer hair cells led to the activation of acetylcholine receptors in outer hair cells and opening the Ca channels. Intracellular Ca increase leads to the opening of $\mathrm{K}$ channels called SK2 [48]. The opening of these channels can increase the stiffness of outer hair cell membrane and reduce the potential changes caused by acoustic stimulation that ultimately reveals itself by decreasing the active amplification of the traveling wave [30,49]. These mechanisms lead to a rapid onset of the effects of MOC activation on outer hair cells and a decrease in the amplitude of the traveling wave associated with the function of outer hair cells in the cochlea.

MOC neurons by releasing acetylcholine and stimulating the entry of Ca into outer hair cells lead to a reduction in the stiffness and skeletal changes in the structure of these cells, and by inducing these slowly (in time as compared to the above effects) affects the amount of activate reinforcement by the outer hair cells [30]. The time constant has estimated for these fast and slow effects in the MOC efferent paths are about $100 \mathrm{~ms}$ and 10 seconds (with their coefficients) [6].

In addition to the direct effects of MOCB on outer hair cells function, stimulation of this pathway, possibly through the outer hair cells, has the potential to reduce the range of the mechanical response of the basilar membrane (BM). The maximum effect was reported on the specific stimulation frequency, which affects the responses of inner hair cells and auditory nerve fibers by increasing the minimum stimulus intensity required and reduces the responses dynamic range [30]. Under certain conditions, the stimulation of the MOCB has shown a slight increase in the vibrations of the basal membrane by unknown mechanisms that cause, and functional outcomes are not known [50].

Regarding the possibility of recording the activity of outer hair cells through the OAE test, stimulation of the contralateral ear can also stimulate the MOCB by stimulating the $\mathrm{CN}$ and SOC reflex arc. Therefore, the OAE Suppression test is the noninvasive method that was used to study the MOCB function and the caudal part of the auditory efferent system. There was still no non-invasive clinical examination for the LOCB in the caudal part of the auditory efferent system. Many studies have shown a reduction in cochlear response as a result of the inhibitory effect induced by MOCB stimulation with the use of contralateral noise in humans $[51,52]$.

With the help of the OAE Suppression test, the function of this part of the caudal auditory efferent system is discussed in many auditory skills and diseases such as auditory neuropathy [53], learning disorders [54], central auditory processing disorder, Dyslexia [56] and Autism [57]. Their results indicate a disorder in the function of the caudal auditory efferent system in several people with these disorders, but they cannot verify the accuracy of the function of the rostral parts of the auditory efferent system.

Considering that cutting off about two-thirds of MOC fibers in the fourth ventricle floor, in many cases, has no impairment in individual functions or has had very minor effects [30], so the functional importance of the MOC and, of course, the LOC in the caudal auditory efferent system is not fully understood. Many studies have been carried out on the functional effects of this part of the auditory efferent system on "protecting the auditory system against noise ", "improving the ability to detect target stimuli and understand speech in the presence of noise", "optimizing the auditory dynamic range", "selective attention 
or dichotic auditory skills" and "sound localization". It should be noted that due to the interaction of the LOCB path with the MOCB in the Corti tunnel, some of these findings may be the result of the LOCB function or interaction between the two parts of the caudal auditory efferent system. At present, there was no information on the functioning and even inhibition or excitation synaptic of the LOCB path [58].

\section{Protection Against Noise}

Crossing fibers of fourth ventricle floor stimulating or contralateral acoustic stimulation, both contribute to the activity of the olivocochlear bundle the medial region, decreases the active enhancement of outer hair cells by reducing the response amplitude and preventing the occurrence of temporary or permanent changes of hearing threshold. Regarding the direct association of MOCB with outer hair cells, it seems that the main contribution to this auditory care is related to MOCB. Although LOCB also has an effect on the transmission of stimulation to auditory nerve fibers to reduce the impact of acoustic trauma on the auditory system but it has probably been shown by correction of the responsiveness of the afferent nerve fibers and not by altering the responsiveness of the outer hair cells [59].

Research has shown that the protective function against acoustic trauma in mice is independent of the number of SK2 channels and the rapid effects of MOCB. It is mainly due to the slow effects of MOCB and the reduction of active enhancement by introducing temporary structural changes in outer hair cells [48]. The protective effects indicated depend on the severity, duration, frequency, and power of the MOCB reflex, the animals with the stronger MOCB reflexes exhibited less threshold changes after severe acoustic stimuli that indicating a greater protective effect $[6,60,61]$. It seems that the power of MOCB reflex can be partly genetically dependent [62].

In addition to noise and acoustic trauma, other harmful agents for the auditory system such as aminoglycoside and ototoxic drugs, also influence the auditory efferent system and MOCB. Studies have shown that some ototoxic drugs such as gentamicin that do not damage hair cells can vary MOCB response depending on the amount of the drug used, depending on the effect on the different neurotransmitters or receptors of outer hair cells or auditory nerve fibers depending on the drug $[63,64]$.

\section{Improving the Ability to Detect Signals and Understand Speech in Noise}

One of the most important functions for the auditory efferent system is its role in detecting a target signal or stimulus in the presence of background noise. Considering further studies and more knowledge about the caudal part of the auditory efferent system the MOCB, there are some theories about the mechanism of the occurrence of this ability at these levels. Animal studies have led to the presentation of the theory of "the antimasking effect of medial olivocochlear bundle". According to this theory, the activity of the MOCB by reducing the cochlear enhancement reduces the response of the nervous system to continuous background noise and reduces the resulting adaptation, therefore by increasing the dynamic range of response, facilitates identifying the slightest changes in tone or each transient signal such as speech for the central nervous system. This seems to be the most important function of MOCB and the auditory efferent system in everyday life and speech perception in the presence of noise $[6,65,66]$.

The review of the articles showed that the method of the studies in the field of the effect of the efferent system MOCB on the ability to detect acoustic signal and speech stimuli in the presence of background noise, can be divided into two general categories:

i. To damage or cut the fibers of the medial olivocochlear bundle.

ii. By examining the correlation between the psychoacoustic performance of individuals and the strength of the medial olivocochlear bundle (MOC).

In the first group of studies in animal samples, MOCB damage led to a reduction in the discrimination between stimuli in cats [67], in human studies, cutting vestibular nerve that the OCB traverses in, leads to disorder of speech perception in noise but in some patients, not in all cases [68].

In the second group studies that relate to the correlation between the psychoacoustic evaluations and the activity of the olivocochlear bundle, they began with the study of the performance of subjects in simpler psychoacoustic tasks such as identifying the stimulus and the intensity discrimination in the presence of noise. These studies indicating the relationship between the discrimination abilities and the activity of the MOC $[69,70]$. Studies on the correlation between the performance of the medial olivocochlear bundle and high-level skills such as speech perception in noise have reported different results.

A significant number of studies have shown that there is a positive correlation between the amount of inhibition induced by the medial olivocochlear bundle and the scores of speech perception in noise [71-73]. These studies reported similar results about the effect of caudal part of the auditory efferent system on the ability of speech perception in noise in normal children [72] and normal adults [73]. However, other studies did not find a meaningful relationship between these two variables $[74,75]$.

Some recent studies that provided precise assessment methods and similar measures to some previous studies have reported even negative correlation and the inverse effect of the medial olivocochlear bundle on the ability of speech perception in noise and lack of meaningful connection in some experimental conditions [76-78]. According to researchers' suggestions, the reasons for the differences in these studies can related to 
the methods of medial olivocochlear reflex evaluation like the used signal to noise ratios and the subject's duty during the examination. These differences can relate to the complex nature of the process for speech perception in noise and the conflict between different auditory and non-auditory processes, which is evaluated in speech in noise tests with different test materials such as syllable, word, and sentence [79-82].

According to the common finding of all the studies, the effect of the medial olivocochlear bundle on the improvement of the signal-to-noise ratio was reported. The findings of the recent papers suggesting that a lack of the relationship between the performance of the medial olivocochlear bundle and speech perception in noise despite the signal-to-noise ratio improvement have noted the role of higher auditory structures in controlling and modifying the purely reflexive function of the medial olivocochlear bundle $[58,76,79]$. Therefore, despite the confirmation of the effect of auditory efferent system on improving the the signal in the presence of noise in normal people and even in people with more auditory experiences, such as bilingual subjects [83], the need to determine the effects of higher levels of auditory efferent system on the speech perception in noise has suggested. The limited studies on the relationship between the rostral and caudal levels of auditory efferent system on the performance of speech perception in the presence of noise have shown the independent effect of these two paths [84], but still a verified assessment method for survey higher levels are not clinically provided just test like S-ABR/coN was suggested recently.

\section{Adapting and Optimizing the Auditory Dynamic Range}

As noted, the effects of the caudal auditory efferent system on the basilar membrane, hair cells and auditory nerves responses and the decrease in the level of activity of the auditory nerves in cases of severe intensity levels stimuli, can improve the dynamic range of the activity of the cochlea and the auditory nerve [30].

\section{Selective Attention and Dichotic Listening Skills}

The role of the efferent auditory system on selective attention was reported [30]. Selective attention is a mechanism that leads to the allocation of cognitive resources and the focus on specific stimuli during separation among a range of nontarget stimuli $[85,86]$. Currently, dichotic listening tasks are considered as valid behavioral criteria for selective attention examine [40]. Selective auditory attention plays an important role in dichotic auditory tasks and is one of the most common problems in central auditory processing disorder $[87,88]$. a shift in the level of OAE suppression following focused attention tasks was reported in cats [89] and in humans [40,90].

In addition, a significant correlation between normal performance in verbal dichotic listening task and $\mathrm{OAE}$ suppression is shown in studies [91]. According to the researchers' suggestions, the verbal dichotic listening task needs to divided attention, which is a cognitive ability that requires a precise central adjustment at high levels. Therefore, the correlation between the results of dichotic behavioral testing and OAE suppression, reinforcing the notion about the control of the rostral part of the auditory efferent system on cochlear and effects on the OAE amplitude. Confirmation the effects of rostral part of the auditory efferent system on the process of selective attention through the impact on the MOCB activity, need further research to identify the role of the rostral part of the auditory efferent system or the direct and independent influence of the caudal part of the auditory efferent system on this skill.

\section{Sound Localization}

Although one of the main functions of the auditory efferent system in everyday life is the discrimination and identification of the signal in the presence of background noise, in addition to that, humans and many animals have to respond appropriately to the sound locations in silence and in challenging noise situations. The localization of sound source is dependent on the intensity, time, and spectral features of the sounds that reach the ears [30] and require the cooperation of various neurological centers, especially the SOC to determine the location of the sound and to work with other sensory-motor systems to send appropriate commands. In addition to the afferent auditory pathways, the pathways for auditory efferent system also play a part in this ability. In a study that investigated the localization of sound in affected MOCB group and control group of cats, weaker performance in the experimental group was confirmed by the role of the auditory efferent pathway in sound localization [92]. Human studies in the area of sound localization in the presence of noise indicate the effect of signal-to-noise ratio on localization accuracy. By increasing the noise intensity or decreasing the signal-to-noise ratio, the score of correct localization has shown a decreasing trend relative to the silence conditions $[93,94]$.

In 2011 a study was conducted to investigate the relationship between the ability of sound localization in noise and the performance of the auditory efferent system in physiological conditions in normal people without hearing impairment. To determine, the correlation between the scores of sound localization in noise and the amplitude of OAE suppression were studied in subjects with normal hearing. The results showed a significant negative correlation. The greater the response of the OAE suppression, the lower sound localization scores decrease in comparison to silence were reported so individuals with more OAE suppression amplitudes showed better performance in sound localization in noise [95]. The participation of the rostral part of the auditory efferent system is also confirmed in sound localization in noise. Therefore, one of the auditory skills related to functions of auditory efferent system is the ability to sound localization in noise.

The less attended areas, such as the effect of auditory efferent pathways on incident or management of tinnitus, have been suggested in studies, in which OAE suppression was recorded in 
patients with tinnitus or hyperacusis [96,97]. Unusual findings such as more TEOAE amplitudes by providing contralateral noise (rather than decrease amplitude) in tinnitus patients, indicates a special need to look at the role of the auditory efferent system in tinnitus occurrence [98].

\section{Discussion and Conclusion}

According to the structural and anatomy studies of the auditory efferent system that show the presence of these pathways from the auditory cortex to the lowest levels of the auditory system means the peripheral receptors, it seems important to determine the function of this system and to evaluate it clinically at different levels. Considering the overall classification of this system based on rostral and caudal levels, the current information from the rostral part, namely corticothalamic and corticocollicular pathways, despite its large volume, cyclic communication with the auditory afferent pathway and the auditory and non- auditory interactions of the major nuclei of this path, like the IC, is negligible.

The need for structural, physiological and electrophysiological studies at rostral levels is obvious. In the caudal part or the olivocochlear bundle, in particular it's a medial part, there is valuable information that indicating the functional significance of this path, especially in challenging auditory skills such as signal detection and speech perception in noise, dichotic listening tasks, creating the optimum dynamic range and sound localization in noise. Considering the availability of OAE-suppression physiological and non-invasive test to examine the reflex of the MOC, it seems that the clinical use of this test in various groups with specific disorders can provide a more comprehensive assessment of the auditory system.

Another important point is the study of the interaction between the two rostral and caudal parts of the auditory efferent system in different auditory processing skills. The attention of researchers in the field of auditory neuroscience will open many research windows to the auditory efferent system.

\section{References}

1. Hall JW (2007) New handbook of auditory evoked responses. ASHA.

2. Rasmussen GL (1953) Further observations of the efferent cochlear bundle. Journal of comparative Neurology 99(1): 61-74.

3. Rasmussen GL (1964) Anatomic relationships of the ascending and descending auditory systems. Neurological aspects of auditory and vestibular disorders 1: 5-19.

4. Rasmussen GL (1946) The olivary peduncle and other fiber projections of the superior olivary complex. Journal of Comparative Neurology 84(2): 141-219.

5. Weedman DL, Ryugo DK (1996) Pyramidal cells in primary auditory cortex project to cochlear nucleus in rat. Brain research 706(1): 97102.

6. Ryugo DK, Fay RR, Popper AN (2010) Auditory and vestibular efferents. Springer Science \& Business Media.

7. Weedman DL, Ryugo DK (1996) Projections from auditory cortex to the cochlear nucleus in rats: synapses on granule cell dendrites. Journal of Comparative Neurology 371(2): 311-24.
8. Winer JA (2005) Decoding the auditory corticofugal systems. Hearing research 207(1-2): 1-9.

9. Winer JA, Larue DT, Diehl JJ, Hefti BJ (1998) Auditory cortical projections to the cat inferior colliculus. Journal of Comparative Neurology 400(2): 147-74.

10. Mulders W, Robertson D (2000) Evidence for direct cortical innervation of medial olivocochlear neurones in rats. Hearing research 144(1-2): 65-72.

11.Spangler K, Warr W (1991) The descending auditory system. Neurobiology of hearing: The central auditory system 27-45.

12. Budinger E, Heil P, Scheich H (2000) Functional organization of auditory cortex in the Mongolian gerbil (Meriones unguiculatus). IV. Connections with anatomically characterized subcortical structures. European Journal of Neuroscience 12(7): 2452-74.

13. Malmierca MS, Anderson LA, Antunes FM (2015) The cortical modulation of stimulus-specific adaptation in the auditory midbrain and thalamus: a potential neuronal correlate for predictive coding. Frontiers in systems neuroscience 9:19.

14. Feliciano M, Saldaña E, Mugnaini E (1995) Direct projections from the rat primary auditory neocortex to nucleus sagulum, paralemniscal regions, superior olivary complex and cochlear nuclei. Aud Neurosci 1: 287-308.

15. Winer JA, Lee CC (2007) The distributed auditory cortex. Hearing research 229(1-2): 3-13.

16. Schochat E, Matas CG, Samelli AG, Carvallo RMM (2012) From otoacoustic emission to late auditory potentials P300: the inhibitory effect. Acta neurobiologiae experimentalis 72(3): 296-307.

17. Winer JA, Larue DT, Huang CL (1999) Two systems of giant axon terminals in the cat medial geniculate body: convergence of cortical and GABAergic inputs. Journal of Comparative Neurology 413(2): 181197.

18. Winer JA, Prieto JJ (2001) Layer V in cat primary auditory cortex (AI): cellular architecture and identification of projection neurons. Journal of Comparative Neurology 434(4): 379-412.

19. Jane JA, Masterton RB, Diamond IT (1965) The function of the tectum for attention to auditory stimuli in the cat. Journal of Comparative Neurology 125(2): 165-191.

20. Schofield B (2009) Projections to the inferior colliculus from layer VI cells of auditory cortex. Neuroscience 159(1): 246-258.

21. Ryugo DK (2011) Introduction to efferent systems. Auditory and vestibular efferents: Springer 1-15.

22. Mitani A, Shimokouchi M, Nomura S (1983) Effects of stimulation of the primary auditory cortex upon colliculogeniculate neurons in the inferior colliculus of the cat. Neuroscience letters 42(2): 185-189.

23. Huffman RF, Henson Jr O (1990) The descending auditory pathway and acousticomotor systems: connections with the inferior colliculus. Brain Research Reviews 15(3): 295-323.

24. Thompson AM (2006) Inferior colliculus projections to pontine nuclei in guinea pig. Brain research 1100(1): 104-109.

25. Thompson AM, Thompson GC (1993) Relationship of descending inferior colliculus projections to olivocochlear neurons. Journal of Comparative Neurology 335(3): 402-412.

26. Vetter DE, Saldaña E, Mugnaini E (1993) Input from the inferior colliculus to medial olivocochlear neurons in the rat: a double label study with PHA-L and cholera toxin. Hearing research 70(2): 173-86.

27. Terreros G, Delano PH (2015) Corticofugal modulation of peripheral auditory responses. Frontiers in systems neuroscience 9: 134. 


\section{Global Journal of Otolaryngology}

28. Aedo C, Terreros G, León A, Delano PH (2016) The corticofugal effects of auditory cortex microstimulation on auditory nerve and superior olivary complex responses are mediated via alpha-9 nicotinic receptor subunit. PloS one 11(5): e0155991.

29. Perales M, Winer JA, Prieto JJ (2006) Focal projections of cat auditory cortex to the pontine nuclei. Journal of Comparative Neurology 497(6): 959-80.

30. Pickles JO (2008) An introduction to the physiology of hearing.

31. Beneyto M, Prieto JJ (2001) Connections of the auditory cortex with the claustrum and the endopiriform nucleus in the cat. Brain research bulletin 54(5): 485-98.

32. Ciuman RR (2010) The efferent system or olivocochlear function bundle-fine regulator and protector of hearing perception. International journal of biomedical science: IJBS 6(4): 276.

33. Liberman MC (1988) Physiology of cochlear efferent and afferent neurons: direct comparisons in the same animal. Hearing research 34(2): 179-191.

34. Liberman M, Brown M (1986) Physiology and anatomy of single olivocochlear neurons in the cat. Hearing research 24(1): 17-36.

35. Zook J, Casseday J (1982) Cytoarchitecture of auditory system in lower brainstem of the mustache bat, Pteronotus parnellii. Journal of Comparative Neurology 207(1): 1-13.

36. Moore JK, Moore R (1971) A comparative study of the superior olivary complex in the primate brain. Folia Primatologica 16(1-2): 35-51.

37. Guinan Jr JJ, Warr WB, Norris BE (1983) Differential olivocochlear projections from lateral versus medial zones of the superior olivary complex. Journal of Comparative Neurology 221(3): 358-370.

38. Ma X, Suga N (2003) Augmentation of plasticity of the central auditory system by the basal forebrain and/or somatosensory cortex. Journal of Neurophysiology 89(1): 90-103.

39. Yan J, Ehret G (2002) Corticofugal modulation of midbrain sound processing in the house mouse. European Journal of Neuroscience 16(1): 119-28.

40. Garinis A (2008) Efferent control of the human auditory system.

41. Ota Y, Oliver D, Dolan D (2004) Frequency-specific effects on cochlear responses during activation of the inferior colliculus in the Guinea pig. Journal of neurophysiology 91(5): 2185-2193.

42. Groff JA, Liberman MC (2003) Modulation of cochlear afferent response by the lateral olivocochlear system: activation via electrical stimulation of the inferior colliculus. Journal of neurophysiology 90(5): 3178-3200.

43. Mulders W, Robertson D (2005) Noradrenergic modulation of brainstem nuclei alters cochlear neural output. Hearing research 204(1-2): 147-155.

44. Darrow KN, Simons EJ, Dodds L, Liberman MC (2006) Dopaminergic innervation of the mouse inner ear: evidence for a separate cytochemical group of cochlear efferent fibers. Journal of Comparative Neurology 498(3): 403-414.

45. Darrow KN, Maison SF, Liberman MC (2006) Cochlear efferent feedback balances interaural sensitivity. Nature neuroscience 9(12): 1474.

46. Ruel J, Nouvian R, d Aldin CG, Pujol R, Eybalin M, et al. (2001) Dopamine inhibition of auditory nerve activity in the adult mammalian cochlea European Journal of Neuroscience 14(6): 977-986.

47. Guinan Jr JJ, Stankovic KM (1996) Medial efferent inhibition produces the largest equivalent attenuations at moderate to high sound levels in cat auditory-nerve fibers. The Journal of the Acoustical Society of America 100(3): 1680-1690.
48. Maison SF, Parker LL, Young L, Adelman JP, Zuo J, et al. (2007) Overexpression of SK2 channels enhances efferent suppression of cochlear responses without enhancing noise resistance. Journal of neurophysiology 97(4): 2930-2936.

49. Murugasu E, Russell I (1996) The role of calcium on the effects of intracochlear acetylcholine perfusion on basilar membrane displacement in the basal turn of the guinea pig cochlea. Auditory Neuroscience 2(4): 363-376.

50. Cooper N, Guinan Jr J (2006) Efferent-mediated control of basilar membrane motion. The Journal of physiology 576(1): 49-54.

51. Collet L, Kemp DT, Veuillet E, Duclaux R, Moulin A, et al. (1990) Effect of contralateral auditory stimuli on active cochlear micro-mechanical properties in human subjects. Hearing research 43(2-3): 251-261.

52. De Ceulaer G, Yperman M, Daemers K, Van Driessche K, Somers T, et al. (2001) Contralateral suppression of transient evoked otoacoustic emissions: normative data for a clinical test set-up. Otology \& neurotology 22(3): 350-355.

53. Starr A, Picton TW, Sininger Y, Hood LJ, Berlin CI (1996) Auditory neuropathy. Brain 119(3): 741-53.

54. Kraus N (2001) Auditory pathway encoding and neural plasticity in children with learning problems. Audiology and Neurotology 6(4): 221-227.

55. Muchnik C, Roth DA E, Othman Jebara R, Putter Katz H, Shabtai EL, et al. (2004) Reduced medial olivocochlear bundle system function in children with auditory processing disorders. Audiology and Neurotology 9(2): 107-114.

56. Canale A, Dagna F, Favero E, Lacilla M, Montuschi C, et al. (2014) The role of the efferent auditory system in developmental dyslexia. International journal of pediatric otorhinolaryngology 78(3): 455-458.

57. Danesh AA, Kaf WA (2012) DPOAEs and contralateral acoustic stimulation and their link to sound hypersensitivity in children with autism. International journal of audiology 51(4): 345-352.

58. Guinan Jr JJ (2014) Olivocochlear efferent function: issues regarding methods and the interpretation of results. Frontiers in systems neuroscience 8: 142 .

59. Darrow KN, Maison SF, Liberman MC (2007) Selective removal of lateral olivocochlear efferents increases vulnerability to acute acoustic injury. Journal of neurophysiology 97(2): 1775-1785.

60. Maison SF, Liberman MC (2000) Predicting vulnerability to acoustic injury with a noninvasive assay of olivocochlear reflex strength. Journal of Neuroscience 20(12): 4701-4707.

61. Rajan R (1995) Involvement of cochlear efferent pathways in protective effects elicited with binaural loud sound exposure in cats. Journal of neurophysiology 74(2): 582-597.

62.Skjonsberg A, Halsey K, Ulfendahl M, Dolan D (2003) Post-onset adaptation before noise exposure in animals shown to be resistant to noise trauma. Assoc Res Otolaryngol Abs 26: 102.

63. Gáborján A, Halmos G, Répássy G, Vizi ES (2001) A new aspect of aminoglycoside ototoxicity: impairment of cochlear dopamine release. Neuroreport 12(15): 3327-3330.

64. Costa DLd, Erre J P, Aran J M (1998) Aminoglycoside ototoxicity and the medial efferent system: I. Comparison of acute and chronic gentamicin treatments. Audiology 37(3): 151-161.

65. Kawase T, Delgutte B, Liberman MC (1993) Antimasking effects of the olivocochlear reflex. II. Enhancement of auditory-nerve response to masked tones. Journal of Neurophysiology 70(6): 2533-2549.

66. Winslow RL, Sachs MB (1988) Single-tone intensity discrimination based on auditory-nerve rate responses in backgrounds of quiet, noise, 


\section{Global Journal of Otolaryngology}

and with stimulation of the crossed olivocochlear bundle. Hearing research 35(2-3): 165-189.

67. MAY BJ, McQUONE SJ (1995) Effects of bilateral olivocochlear lesions on pure-tone intensity discrimination in cats. Auditory neuroscience 1(4): 385

68. Zeng F G, Martino KM, Linthicum FH, Soli SD (2000) Auditory perception in vestibular neurectomy subjects. Hearing research 142(1-2): 102-112.

69. Micheyl C, Perrot X, Collet L (1997) Relationship between auditory intensity discrimination in noise and olivocochlear efferent system activity in humans. Behavioral neuroscience 111(4): 801.

70. Micheyl C, Collet L (1996) Involvement of the olivocochlear bundle in the detection of tones in noise. The Journal of the Acoustical Society of America 99(3): 1604-1610.

71. Giraud AL, Garnier S, Micheyl C, Lina G, Chays A, et al. (1997) Auditory efferents involved in speech-in-noise intelligibility. Neuroreport 8(7): 1779-1783

72. Kumar UA, Vanaja C (2004) Functioning of olivocochlear bundle and speech perception in noise. Ear and hearing 25(2): 142-6.

73. De Boer J, Thornton ARD (2008) Neural correlates of perceptual learning in the auditory brainstem: efferent activity predicts and reflects improvement at a speech-in-noise discrimination task. Journa of Neuroscience 28(19): 4929-4937.

74. Wagner W, Frey K, Heppelmann G, Plontke SK, Zenner H P (2008) Speech-in-noise intelligibility does not correlate with efferent olivocochlear reflex in humans with normal hearing. Acta otolaryngologica 128(1): 53-60.

75. Mukari SZ MS, Mamat WHW (2008) Medial olivocochlear functioning and speech perception in noise in older adults. Audiology and Neurotology 13(5): 328-334.

76. De Boer J, Thornton ARD, Krumbholz K (2011) What is the role of the medial olivocochlear system in speech-in-noise processing? Journal of neurophysiology 107(5): 1301-1312.

77. Stuart A, Butler AK (2012) Contralateral suppression of transient otoacoustic emissions and sentence recognition in noise in young adults. Journal of the American Academy of Audiology 23(9): 686-696.

78. Mishra SK (2014) Medial efferent mechanisms in children with auditory processing disorders. Frontiers in human neuroscience 8: 860

79. Mishra SK, Lutman ME (2014) Top-down influences of the medial olivocochlear efferent system in speech perception in noise. PLoS One $9(1)$ : e85756

80. Lotfi Y, Kargar S, Javanbakht M, Biglarian A (2016) Development, Validity and Reliability of the Persian Version of the Consonant-Vowel in White Noise Test. Journal of Rehabilitation Sciences and Research 3(2): 29-34

81. Arbab H, Moossavi A, Javanbakht M, Bakhsh E, MahmoodiBakhtiari B, et al. (2017) Development and Psychometric Evaluation of Persian version of the Quick Speech in Noise Test in Persian Speaking 1825 Years Old Normal Adults. Journal of Rehabilitation Sciences and Research 3(3): 51-56.

82. Lotfi Y, Salim S, Mehrkian S, Ahmadi T, Biglarian A (2016) The Persian version of words-in-noise test for young population: development and validation. Auditory and Vestibular Research 25(4): 194-200.
83. Lotfi Y, Chupani J, Javanbakht M, Bakhshi E (2018) Evaluation of speech perception in noise in Kurd-Persian bilinguals. Auditory and Vestibular Research 36-41.

84. Maruthy S, Kumar UA, Gnanateja GN (2017) Functional Interplay Between the Putative Measures of Rostral and Caudal Efferent Regulation of Speech Perception in Noise. Journal of the Association for Research in Otolaryngology 18(4): 635-648.

85. Lehmann A, Schönwiesner M (2014) Selective attention modulates human auditory brainstem responses: relative contributions of frequency and spatial cues. PloS one 9(1): e85442.

86. Gazzaley A, Nobre AC (2012) Top-down modulation: bridging selective attention and working memory. Trends in cognitive sciences 16(2): 129-135.

87. Bryden M, Munhall K, Allard F (1983) Attentional biases and the rightear effect in dichotic listening. Brain and language 18(2): 236-248.

88. Alamdari S, Lotfi Y, Yazdi AK, Javanbakht M, Bakhshi E (2018) Effects of Chronic Otitis Media with Effusion on Amblyaudia. Journal of Rehabilitation Sciences and Research 5(3): 63-67.

89. Hernandez Peon R, Scherrer H, Jouvet M (1956) Modification of electric activity in cochlear nucleus during attention in unanesthetized cats. Science 1(956): 123

90. De Boer J, Thornton ARD (2007) Effect of subject task on contralateral suppression of click evoked otoacoustic emissions. Hearing research 233(1-2): 117-123

91. Markevych V, Asbjørnsen AE, Lind O, Plante E, Cone B (2011) Dichotic listening and otoacoustic emissions: Shared variance between cochlear function and dichotic listening performance in adults with normal hearing. Brain and cognition 76(2): 332-339.

92. May BJ, Budelis J, Niparko JK (2004) Behavioral studies of the olivocochlear efferent system: learning to listen in noise. Archives of Otolaryngology-Head \& Neck Surgery 130(5): 660-664.

93. Kerber IS, Seeber IBU (2012) Sound localization in noise by normalhearing listeners and cochlear implant users. Ear and hearing 33(4): 445 .

94. Best V, Carlile S, Jin C, van Schaik A (2005) The role of high frequencies in speech localization. The Journal of the Acoustical Society of America 118(1):353-363.

95. Andéol G, Guillaume A, Micheyl C, Savel S, Pellieux L, et al. (2011) Auditory efferents facilitate sound localization in noise in humans. Journal of Neuroscience 31(18): 6759-6763.

96. Riga M, Komis A, Maragoudakis P, Korres G, Ferekidis E, et al (2018) Objective assessment of subjective tinnitus through contralateral suppression of otoacoustic emissions by white noise: effects of frequency, gender, tinnitus bilaterality and age. Acta Otorhinolaryngologica Italica 38: 131-137

97. Veuillet E, Khalfa S, Collet L (1999) Clinical relevance of medial efferent auditory pathways. Scandinavian Audiology Supplementum 51: 53-62.

98. Attias J, Bresloff I, Furman V (1996) The influence of the efferent auditory system on otoacoustic emissions in noise induced tinnitus: clinical relevance. Acta oto-laryngologica 116(4): 534-539. 
(C) Commons Attribution 4.0 License Commons Attribution 4.0 License
DOI: $10.19080 /$ GJO.2019.20.556050
Your next submission with Juniper Publishers will reach you the below assets

- Quality Editorial service

- Swift Peer Review

- Reprints availability

- E-prints Service

- Manuscript Podcast for convenient understanding

- Global attainment for your research

- Manuscript accessibility in different formats

( Pdf, E-pub, Full Text, Audio)

- Unceasing customer service

Track the below URL for one-step submission https://juniperpublishers.com/online-submission.php 